\title{
LA NACIÓN ESPAÑOLA ES LA REUNIÓN DE TODOS LOS ESPAÑOLES DE AMBOS HEMISFERIOS
}

\author{
ALEJANDRO RODRÍGUEZ RODRIGO
}

Universidad de Valencia 
Desde 1808 hasta 1824, España e Hispanoamérica conocieron profundas transformaciones políticas, sociales y económicas que marcaron su posterior desarrollo. Estas transformaciones históricas pueden ser concatenadas a través del eje motriz que supuso la Constitución de 1812.

La Constitución de 1812 implicó un cambio en el orden político y social de la época, proyectándose en los movimientos liberales europeos e iberoamericanos como bandera ideológica e inspirando muchos de los textos constitucionales de estos países, que en sus procesos emancipadores o de consolidación como naciones independientes, siguieron el texto de la norma gaditana. La Constitución de Cádiz suponía la culminación de todo un proceso de cambio hacia un sistema de valores completamente nuevo y largamente esperado.

Con objeto de conmemorar la promulgación de la Constitución liberal española de 1812, la Embajada de España y la Pontificia Universidad Católica del Ecuador (PUCE), organizaron las Jornadas de Estudio Conmemorativas del Bicentenario de la Constitución de Cádiz, los días 24 y 25 de octubre de 2012, celebradas en las instalaciones de la PUCE, en el transcurso de las cuales se repasó la construcción de las sociedades modernas en los países del continente, los poderosos vínculos entre las dos orillas del Atlántico y las profundas consecuencias en el modelo de convivencia ecuatoriano de entonces.

\section{EMBAJADA DE ESPAÑA EN ECUADOR}

Las Jornadas de Estudio Conmemorativas del Bicentenario de la Constitución de Cádiz han tratado de profundizar en el estudio de las circunstancias que rodearon la promulgación de la Constitución liberal española de 1812 , con todo el significado y consecuencias que tuvo para la América española y con un especial hincapié en mostrar la realidad ecuatoriana en este momento. Las jornadas contaron con la participación de seis doctores ecuatorianos de la Universidad Central del Ecuador, de la Pontificia Universidad Católica de Ecuador y de la Universidad San Francisco de Quito y del doctor español José María Portillo de la Universidad del País Vasco, quienes desde distintas perspectivas y enfoques, ayudaron a dar luz sobre un momento fundamental en la historia de las dos naciones, que ha quedado oscurecido por leyendas y distorsiones históricas, y olvidado de la memoria colectiva de ambos pueblos. El conocimiento de la realidad de aquellos debates y situaciones políticas no puede dejar de sorprendernos, al ver cómo las mismas cuestiones de antaño aún se encuentran vivas en este siglo XXI.

Las jornadas se dividieron en dos mesas temáticas analíticas:

Mesa I. La Constitución de Cádiz. Perspectiva española. Donde se analizó la importancia de la Constitución gaditana en el desarrollo del pensamiento constitucional latinoamericano y la labor de los diputados americanos en las sesiones constituyentes de Cádiz.

Su moderador fue el Dr. Carlos Paladines y los ponentes: Dr. Carlos Landázuri, Dra. Sabrina Guerra y el Dr. José María Portillo.

Mesa II. La Constitución de Cádiz: Percepciones y permanencias ecuatorianas. Donde se analizó el impacto de la Constitución gaditana en la realidad ecuatoriana del primer tercio del S. XIX y las particularidades ecuatorianas en el primer tercio del $\mathrm{S}$. XIX. 
El moderador fue el Dr. José María Portillo y los ponentes: Dr. Juan Pablo Aguilar, Alejandro Carrión, Dr. Carlos Freile y el Dr. Carlos Paladines.

A continuación se presentan las ponencias que se expusieron en estas jornadas, que esperamos puedan servir como ejemplo de colaboración entre la Embajada de España y la comunidad universitaria ecuatoriana.

No queremos dejar de agradecer el desinteresado apoyo de la Dra. Bertha García, de la Pontificia Universidad Católica del Ecuador, sin cuyo entusiasmo y dedicación estas jornadas no se hubieran podido llevar a cabo. Y de la buena disposición del Dr. Iván Oñate, director de la revista ANALES sin cuyo desprendido consentimiento $y$ respaldo no hubiera sido posible publicar estas interesantes ponencias. 